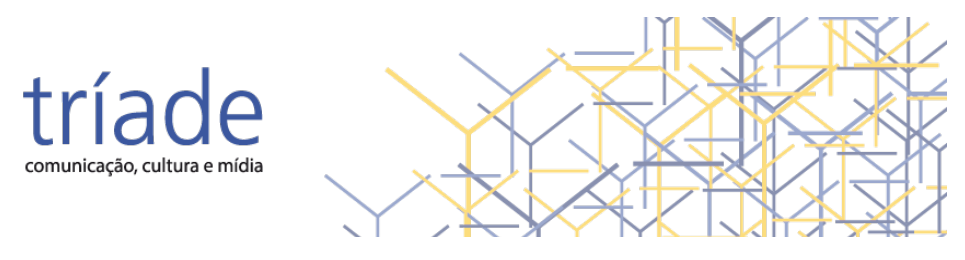

\title{
Faces e interfaces educomunicativas ${ }^{1}$
}

\author{
Educommunicative faces and interfaces \\ Fazes e interfazes de la educomunicación
}

\begin{abstract}
Adilson Citelli - Universidade de São Paulo | São Paulo | São Paulo | Brasil | citelli@uol.com.br I (D) https://orcid.org/0000-0002-0838-9917.
\end{abstract}

\begin{abstract}
Resumo: A partir de trabalho que realizamos no âmbito do grupo de pesquisa MECOM, cujos resultados podem ser encontrados em: http://www2.eca.usp.br/mecom/, voltado a reconhecer e analisar questões postas nos vínculos comunicativo-educativos em escolas do ensino básico, retiramos algumas categorias a serem discutidas neste artigo. Fixamos, em particular, o conceito de interface enquanto núcleo para o qual convergem e do qual se expandem fatores que precisam ser considerados para avançar o debate sobre a educomunicação. Em síntese, procuramos expor e problematizar vetores estruturais e culturais cuja perscrutação é necessária quando se objetiva a tratar dos nexos da comunicação nos ambientes de ensino-aprendizagem.
\end{abstract}

Palavras-chave: Educomunicação. Interfaces. Estruturas. Escola.

Abstract: Based on the work we carried out within the scope of the MECOM research group, the results of which can be found at http://www2.eca.usp.br/mecom/, aimed at recognizing and analyzing issues raised in the communicative-educational links in schools in the basic education, we removed some categories to be discussed in this article. In particular, we have fixed the concept of interface as a nucleus into which factors that need to be considered to expand in order to advance the debate on educommunication are expanding. In summary, we seek to expose and problematize structural and cultural vectors whose scrutiny is necessary when the objective is to deal with the nexus of communication in teaching-learning environments.

Keywords: Educommunication. Interfaces. Structures. School.

Resumen: Del trabajo que realizamos en el grupo de investigación MECOM, cuyos resultados se pueden encontrar en http://www2.eca.usp.br/mecom/, orientado a reconocer y analizar las cuestiones que se plantean en los vínculos comunicativoeducativos en la educación básica, extraemos algunas categorías que se discutirán en este artículo. Fijamos, en particular, el concepto de interfaz como un núcleo al que convergen y desde el

${ }^{1}$ Sob o título de Educomunicação: entre atos, a versão preliminar do presente artigo foi discutida no GP Comunicação e Educação do XXXXIII Congresso Brasileiro de Ciências da Comunicação, Salvador. BA, 2020. O que se lerá resulta de ajustes e acréscimos decorrentes seja dos diálogos com os/as participantes daquele encontro seja da expansão da pandemia do coronavírus neste 2021. 
que se expanden los factores que hay que considerar para avanzar en el debate sobre la educomunicación. En síntesis, buscamos exponer y problematizar vectores estructurales y culturales cuyo escrutinio es necesario cuando pretendemos abordar el nexo de la comunicación en los ambientes de enseñanza-aprendizaje.

Palabras clave: Educomunicación. Interfazes. Estructuras. Escuela.

Recebido em abril 2021 - Aprovado em abril 2021. 


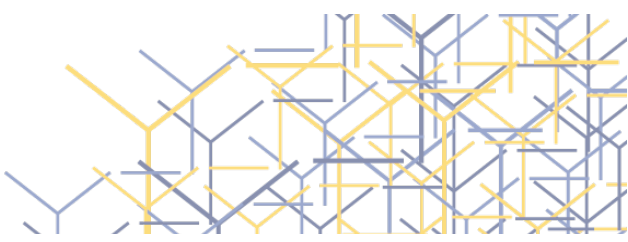

\title{
1 Introdução
}

\begin{abstract}
A tradição dos oprimidos nos ensina que o "estado de exceção" em que vivemos é na verdade a regra geral (Walter Benjamin, 1987).
\end{abstract}

A pergunta que se impõe nesta quadra histórica assolada por uma tragédia sanitária de dimensões impensáveis é como escrever artigo acadêmico alegando desconhecimento do permanente estado de exceção. À maneira do anjo pintado por Paul Klee, no quadro Angelus Novus, conforme entendimento de Walter Benjamin (1987), o que se esclarece são os escombros, a ruinaria, o féretro repetido mais de um milhão de vezes nas várias partes do mundo. E há os nossos próprios doentes e mortos, assim como as vítimas colaterais abandonadas à margem, haja vista que a sociedade desigualitária (PIKETTY, 2020) resolveu entregar a compaixão e o sentimento mais elementar de solidariedade e de justiça ao movimento nervoso dos operadores de mercado presos ao cristal líquido das telas, aos profetas de espírito contabilista, aos ecocidas encastelados em órgãos governamentais que deveriam cuidar do meio ambiente, aos populistas acalentadores de milícias e projetos econômicos que não se envergonham de punir os já punidos e prognosticar um futuro venturoso cujo passado construído ao som das trombetas apocalípticas teima em se avolumar. E no meio da devastação surge um enigma exposto na locução "novo normal"; resta indagar em que momento o estado de exceção foi suspenso neste "vale onde soam os lamentos e impera o grande frio", conforme passagem de Bertold Brecht na Ópera os três vintes, recuperada por Walter Benjamin (1987) nas Teses sobre o conceito de história, aqui em apropriação livre e adaptada às atuais circunstâncias brasileiras.

O fato é que as afirmativas postas neste artigo irão se alinhavar sob o signo da precariedade e o sintagma "em tempos de pandemia", cujo uso reiterado convive nas franjas da naturalização, passa a representar um 
arranjo de linguagem que localiza no imponderável a força redentora de alguma esperança vinda do paraíso. Caso pudesse ter lido tal estereótipo, o anjo de Paul Klee manifestaria inúmeras dúvidas, pois se a doença e o seu tempo podem estar demarcados pela função salvífica das vacinas, o cortejo das iniquidades é a única certeza de prosseguimento, a menos que as trombetas da boa anunciação consigam escrever uma história "escovada a contrapelo" (BENJAMIN, 1987, p. 224).

No momento em que nos encontramos, abril de 2021, fomos requisitados a acertar o rumo do astrolábio (já que existe no governo federal um namoro com a regressão ao medievo, não cabe fazer menção, sequer, à bússola) com o navio em movimento, sobre águas tempestuosas, sem poder reconhecer a posição das estrelas. E não foi por falta de aviso, pois tivemos, no Brasil, particularmente na primeira infestação pelo coronavírus, em torno de quatro meses para tomar alguma providência. Desde que o SARS-CoV-2 migrou do pangolim ou de morcegos - há dúvidas sobre o assunto, malgrado as indicações sinalizarem para o Chiroptera - para algum infausto asiático, e daí ao sexagenário que o trouxe da Itália para São Paulo, não faltaram avisos de que o bicho estava chegando.

Ocorre que o Presidente da República Federativa do Brasil resolveu fazer blague com o assunto, comparando o surto da Covid-19 a um simples resfriado ou gripezinha, informando que de uma ou outra maneira todo mundo morre, entendendo residir no distanciamento social/quarentena (o fecha geral, na expressão do alto dignitário) coisa de fraco, receitando $o$ uso de cloroquina e da hidroxicloroquina, medicamentos utilizados, sob controle médico, no combate à malária, ao lúpus, artrite, algumas formas de porfiria, mas sem indicação específica no caso do Corona.

Furtemo-nos a alongar a lista com os espectros do desastre sanitário, com mais de trezentos mil mortos. É preciso acrescentar, porém que os males de nossa ruinaria se expandem por outros territórios, 


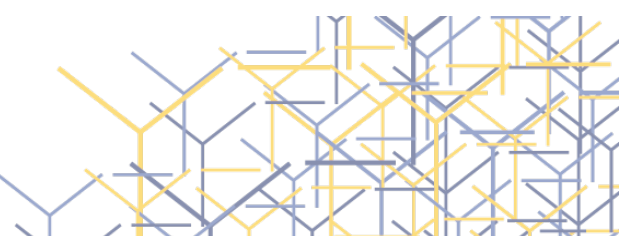

sobretudo aqueles da cultura e da educação, diretamente vinculados ao assunto deste artigo. No primeiro caso, o vetor ideológico a compor o roteiro doutrinário do governo federal em curso foi guerrear contra um fantasmático marxismo cultural, combate cujo mister seria o de apagar temas que estariam assombrando o nosso país desde a redemocratização - daí ser imperioso colocar freios à arte, à pretensa imoralidade reinante nos filmes e programas de televisão, assim como destacar a presença dos assuntos religiosos, dos símbolos patrióticos, da família tradicional, e tutti quanti. No segundo, o projeto desconstrucionista avançou sobre a educação. $O$ que se vem assistindo, nas ramificações com as áreas de ciência, tecnologia e inovação, é um desfile de absurdos, cujo tamanho promete alargar o abismo à nossa frente e apenas tornado mais claro pelo momento pandêmico. Falta de projetos (em outro sentido poder-se-ia ler a lacuna como positividade aliada ao roteiro de destruição), paralisia, retenção ou corte de verbas, desqualificação de professores e professoras, intervenção na autonomia universitária, desinteresse pela pesquisa; considerando tudo isto, a locução "novo normal" é compreensível quando associada ao estado de exceção.

Somadas as duas circunstâncias patogênicas, a do coronavírus - o mal em estado bruto a se alimentar da invisibilidade, do descaso e da teratologia patente na disfuncionalidade governamental - e o da necropolítica (MBEMBE, 2018) - ecoando na fragilização democrática do país - resta inteligível a expressão fixada no rosto do anjo de Paul Klee: afinal, nestes tempos turvos não faltam "mortos faladores e nostalgias de bailado" (ANDRADE, 2012) 2 . O instante de perigo em cena é o da banalização do mal, da normalização de uma história na qual o falso

\footnotetext{
2 Paulo Freire ensina, a partir de diálogo com o livro The heart of man, de Erich Fromm, que ao se reduzir os seres humanos a coisas, ao se intensificar os processos de dominação, o que se revela é a necrofilia negadora da biofilia. Malgrado os anos que nos separam da Pedagogia do oprimido (escrito em 1968, quando o autor estava no exílio chileno, e posto em circulação no Brasil, apenas, em 1974), assistimos a trágica reatualização do anjo da história, que sintetiza a retórica do genocídio no termo necropolítica.
} 
ganha ares de verdade, o apresentado como informação assume o status de acontecimento - e o que é acontecimento se dilui na informação: a se ver as operações de despiste fomentadas por algumas autoridades públicas quando advém o assunto da pandemia. É o que nos leva a entender melhor a assertiva, em adaptação livre, feita pelo professor Mattos, personagem do romance de Cristovão Tezza (2020), A tensão superficial do tempo: o Brasil atravessa período no qual a burrice tornouse ostensiva e orgulhosa. O jogo de sentidos e as inversões valorativas ganham, aqui, caráter autoexplicativo.

Nos interstícios deste quadro buscamos elaborar o presente artigo, que por vias distintas, recoloca a necessidade de aproximar os vínculos comunicação-educação. Isto é, estamos frente a dois dos elementos que se projetam no miolo das dinâmicas sociais, os media, as redes digitais, o fluxo de produção, circulação e recepção de mensagens (em suas diferentes faces e envolvimentos na vasta luta pelo poder representacional e simbólico), e a educação (compromissada, em princípio, com os processos emancipadores). Pensá-los na confluência educomunicacional implica encontrar os liames, os elos de ligação forjados no chão histórico no qual nos movemos. Noutros termos: como tratar da educação formal sem considerar os inúmeros fatores que a ensejam - os rumos das políticas públicas para a área; a formação docente, haja vista os apelos do ensino remoto, híbrido, a distância; as literacias midiáticas; o entendimento do lugar das tecnologias (em boa monta mergulhadas num amálgama de interesses políticos e econômicos de que serve como exemplo metonímico o poder das big techs); a profunda desagregação social brasileira, apenas evidenciada pela crise pandêmica?

Enfim, não parece difícil entender que as aproximações comunicativo-educativas precisam ocorrer, acompanhando a ideia de cenários e inter-relações. Por isso, e para realizarmos breve exercício de acompanhamentos dos processos educomunicativos, elencamos algumas variáveis conceituais e operacionais sumariadas em quatro pontos: 


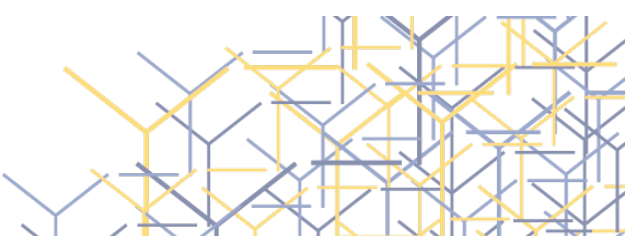

interfaces; desdobramentos estruturais; intercorrências culturais e dimensões do aprender.

\section{Interfaces}

A premissa orientadora da nossa visagem acerca dos nexos comunicação e educação está assentada no pressuposto de que as duas áreas possuem suas próprias interrogantes, metodologias, problemas de pesquisa, áreas de intervenção social, mecanismos de acionamento, para alinharmos algumas linhas de força. Tal aparato ganha tradução em dispositivos e linguagens de que servem como exemplos as salas de aulas, as páginas das revistas e jornais, os produtos televisivos, as telas do computador, as redes sociais. Daí a larga tradição nas quais estão lastreadas, reunindo miríades de estudos acadêmicos, experiências, práticas, versando, de um lado, sobre temas pedagógicos, estratégias de ensino-aprendizagem, e, de outro, envolvendo a imprensa, inovações formais da televisão, poder midiático, alcances comunicacionais da digitalização. Sinteticamente: esclarecem-se ramos do conhecimento que destacam as suas particularidades e singularidades, a despeito de manifestarem os inescapáveis vínculos entre eles, ou, se quisermos, retroalimentando-se de instigações fertilizadoras comuns.

Trata-se, agora, contudo, de aduzir um terceiro elemento no interior do qual seja possível visualizar o constituinte propriamente educomunicativo. A preocupação de esclarecer os liames deste eventual novo campo ${ }^{3}$ de reflexão, pesquisa e intervenção social advém, sobretudo, das mudanças que marcaram as relações e os instrumentos de produção, assim como as demais relações sociais nas últimas décadas do

${ }^{3} \mathrm{O}$ conceito de campo está sendo avocado no sentido exposto por Pierre Bourdieu, haja vista dizer respeito, também, a dimensões de afirmação política e disputas de poder no terreno intelectual e dos embates acadêmicos. Como sabemos, as escolhas retóricas e a formulação de "novos verbetes de dicionários" podem fazer parte do jogo mais amplo voltado a afirmar regiões de domínio, prestígio, reconhecimento, distinção, todos eles fatores simbólicos e de representação que circundam os percursos universitários. 


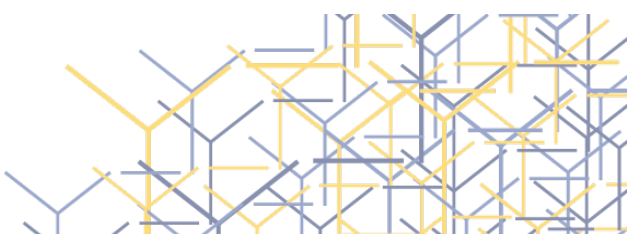

século XX e de crescente presença em nossa centúria. A maneira de nomear esse âmbito pode variar, conquanto guardem diferenças internas, de que seguem alguns exemplos: na tradição anglo-saxônica encontramos Media Literacy, Media Education, Digital Literacy in Education, Education in Media Literacy; na França, Competénce Mediatique, Éducation aux Médias; na Itália, Educazione ai Media; na América espanhola e Espanha, Educación en Medios, Educación para la Comunicación; no Brasil, Educomídia, Pedagogia da Comunicação, Educação Midiática, Comunicação e Educação, Literacia Digital, Educomunicação.

É preciso considerar, porém, que malgrado os designadores estamos indicando existirem "zonas de interface" que nos possibilitam identificar quais são os "nós da rede" a vincularem comunicação e educação. A tendência redutora é crer que a dita área de convergência pode ser suprida, direta ou quase exclusivamente, por fontes técnicocomunicacionais, entendimento provável resultante do lugar especioso por elas ocupados em nossa quadra histórica. Aduza-se que as pesquisas referentes aos liames comunicação e educação mostram continuadamente o crescimento da presença e importância dos dispositivos nas salas de aula, sobretudo dos celulares - independentemente de estarem ou não sendo utilizados para finalidades didáticas. A pesquisa do MECOM, a que fizemos referência, efetivada com o propósito central de investigar hábitos midiáticos por docentes e discentes em unidades de ensino básico brasileiro, envolvendo quinhentos e nove professores e professoras e três mil setecentos e oito alunos e alunas, comprova a afirmativa posta acima consoante ao aumento no volume e no significado dos recursos da comunicação no circuito educativo formal ${ }^{4}$.

\footnotetext{
4 Sob o título Inter-relações Comunicação e Educação no contexto do ensino básico, a investigação foi apoiada pelo Conselho Nacional de Desenvolvimento Científico e Tecnológico (CNPq). E realizada no âmbito do Grupo de Pesquisa Mediações Educomunicativas (MECOM), por mim coordenado. Para acesso amiúde ao material, consultar o endereço eletrônico referido no resumo deste artigo.
} 
Ademais, a profusão e miniaturização dos equipamentos digitais ao trazer consigo a percepção do tempo socialmente acelerado (CITELLI, 2017), da imaterialidade e do estreitamento espacial, pode promover o equívoco segundo a qual nas "zonas de interface" residem, apenas, aparelhos de televisão e rádio, powerpoint, celular, computador, e variações do gênero. Partimos de outra perspectiva e nela vige a ideia de que é reducente conectar à educomunicação o domínio exclusivo das técnicas e dos equipamentos - tentação sempre presente na evocação dos nexos media-escola, nos apelos à modernização das salas de aula. Em pequeno adendo: é bom lembrar que a visão da técnica como instância autônoma foi criticada por Martin Heidegger (2002). Em vários dos seus escritos, o pensador alemão distingue as duas essências da técnica: uma manifesta na teckné grega e a outra na tecnologia moderna. A primeira vem associada ao sentido originário de techné (poiesis/produção) e a segunda, a moderne technik, seguiu os caminhos da gestell (composição). Ao deixar o terreno da poiesis (criação), os seres humanos ficaram à disposição (bestand) da técnica como algo que tudo arrasta e sobre a qual não possuem domínio, tendo-a, apenas, como fenômeno de reprodução ou composição. Nesse caso, é possível falar em globalização tecnológica (uma "planetarização" da gestell), algo a expressar, nos tempos correntes, uma estratégia de "neocolonização que impõe sua racionalidade via instrumentalidade" (HUI, 2020, p. 41).

Para evitar as armadilhas à espreita das literacias midiáticas, a seguirmos com aquela tensão heideggeriana, é imperioso tratar da "zona de interface" desdobrando-a nos três próximos itens - passíveis de análise nos limites deste artigo - e que ajudam a delinear os vínculos comunicativo-educativos. 


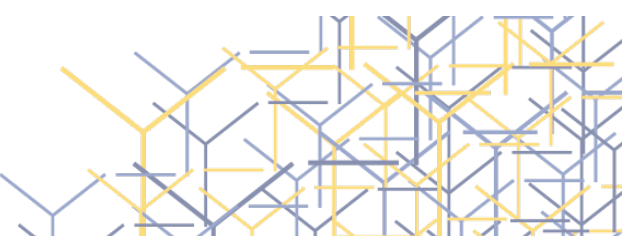

\section{Dimensões estruturais}

O desenvolvimento do capital vem sendo acompanhado de mudanças substantivas em suas dinâmicas econômicas (difusão dos modelos "thatcheristas"), tecnológicas (centralidade da telemática), de organização do estado (privatizações), trabalhistas (desregulamentação), políticas (crescimento do populismo, do liberalismo, fragilização da democracia). As mutações tecnocientíficas ganharam profundidade e extensão, trazendo consigo aumento na velocidade e espalhando o uso dos dispositivos técnicos. O velho capitalismo mecânico-industrial passa por crescentes níveis de fragilização, sendo gestado em seu lugar novos conceitos, práticas e mesmo uma nomenclatura própria: capitalismo de dados, de atenção, digital. Pairando sobre o conjunto estão a inteligência artificial, os algoritmos, as grandes bases de dados. Os operadores decisivos do sistema, há poucos anos companhias automobilísticas e de aviação tiveram que dividir os seus reinados, quando não os perderam para outros senhores mais jovens que atendem pelos nomes de Alphabet (controladora do Google), Microsoft, Facebook, Apple, Verizon, Tencent (entre outras coisas, o maior portal de serviços da internet da China), etc.

Na outra ponta deste movimento, mas a ele diretamente conectado, emerge a capacidade de o capital produzir uma sociedade marcada pela enorme concentração de renda e aprofundamento das desigualdades sociais, conquanto a utilização de retórica que confere à concorrência, ao espírito empreendedor, à liberdade econômica à desregulamentação e à diminuição do estado a possibilidade de construir o paraíso na terra.

Nesse cenário, os modos de funcionamento da comunicação e da educação passam por deslocamentos, certamente em níveis, graus e alcances diferentes. Apenas para esclarecer alguns pontos da assertiva geral: os sistemas e processos comunicacionais, ao mesmo passo em que jogam papel importante na definição das linhas de força dos novos modos de organização do capital, são impelidos a rever constantemente a 
infraestrutura tecnológica dos seus negócios, efetivando os consequentes rearranjos no terreno da linguagem e dos padrões estéticos. Daí, por exemplo, as mudanças nos jornais impressos - tanto em termos formais como de sustentação econômica - que assistem à crescente migração dos leitores para as bases digitais. Tal circunstância traz consigo resultantes, seja no tangente à necessidade de investimentos continuados em tecnologia da informação seja nos hábitos do público - agora afeito a operar telas, ativar os movimentos hápticos, buscar notícias em ritmo de fragmentação e celeridade.

A educação, por sua vez, tem duplo problema a resolver. De um lado, não pode agir como simples peça para ajustar os sujeitos ao referido realinhamento estrutural $e$, de outro, sofre as resultantes de um desencontro entre a aceleração tecnológica e as estratégias didáticas e pedagógicas exercitadas nas escolas, ainda fortemente propedêuticas e verbalistas - tema cuja complexidade requisita ampliação noutro momento.

Verificamos, porém, ao ligarmos as referidas mudanças estruturais que matizam a sociedade coeva aos procedimentos da comunicação e da educação, o afloramento de área capaz de contribuir na produção de um tipo de conhecimento gestado na "zona de interface" e a se voltar de modo mais decisivo ao trabalho nos diversos âmbitos educativos: formais, informais e não formais. Certamente os problemas suscitados na interface possuem inúmeras imbricações, das quais destacamos duas a título ilustrativo: a) as perspectivas acerca da comunicação e educação nem sempre são afinadas em propósitos e objetivos. Certos segmentos da comunicação revelam pouco ou nenhuma divergência com a defesa do, chamemos assim, núcleo duro que ordena o capital, resultando de forma dominante em práticas de ajustamento - malgrado empresas de jornalismo, televisão, plataformas digitais possam entrar em liça momentânea com políticas governamentais, partidos, grupos de pressão, etc.); b) a educação, pelo menos como a pensamos, requisita 
compromisso libertador, havendo que fugir das solicitações reguladoras, ora proclamadas pelo mercado e mesmo pelo Ministério da Educação neste caso, basta acompanhar as declarações dos ministros que assumiram o cargo; quatro em pouco mais de dois anos, sendo que um deles experimentou a glória por apenas cinco dias. Outrossim, há um desafio a ser enfrentado pela escola concernente às sociotécnicas, centrais nos processos de comunicação, e de larga presença na vida cotidiana, mas pouco incorporada sob a perspectiva cultural (ou da acima mencionada techné) na educação processada em sala de aula.

\section{Intercorrências culturais}

Tratamos de pensar a questão da interface, segundo vem sendo assinalado, como instância para onde convergem linhas de força e entre as quais apresenta-se a cultura. O vigor estratégico da comunicação e das sociotécnicas, por vias muitas vezes próprias, estão ajudando a reorientar percepções, compreensões, atitudes e práticas dos sujeitos, ganhando extensão no plano das afetividades, comportamentos e sociabilidades, para situarmos vetores a serem facilmente deduzidos e completados.

A vivência com as "máquinas de contato" (ou dispositivos comunicacionais), em sua pluralidade de telas e suportes, não apenas solicita o domínio físico de tais objetos, mas pressupõe reconhecer que com eles circulam marcas culturais, aquelas formas representativas e simbólicas substanciadas em linguagens a manifestarem determinados entendimentos acerca da ordem do mundo. Essa teia de reorientações e ressignificações que atravessa o terreno da cultura e das suas óbvias ligações com a vida associativa é fortemente transitada através dos mediadores tecno-comunicacionais.

A velocidade das operações hápticas realizadas através dos tablets ou smartphones conectados à internet gera a atitude ansiosa de saltar entre likes e disparos sem que exista necessária relação a imantá-los: os 


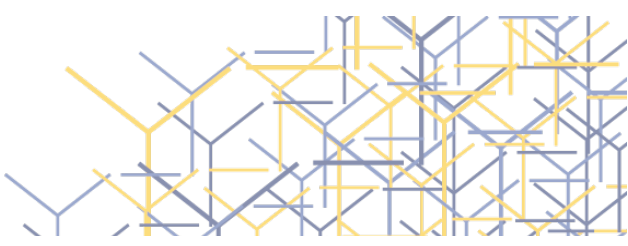

assuntos são vários, os interesses múltiplos e a celeridade uma espécie de obrigação. A procura, muitas vezes chamada pela escola de pesquisa, dilui um certo procedimento que acompanhava a lógica formal, em sua disposição de começo, meio e fim, tudo devidamente apoiado em provas e argumentos. Evidencia-se na utilização intensiva das "máquinas de contato" o andamento agitado que antevê no processo de desaceleração não apenas perda de tempo, mas comprometimento "metodológico" em se obter mais com menos - ajuntamento de informação em período curto de minutos. $E$, aparentemente, pouco resta a fazer quanto a isto porque partícipe das estratégias acumulativas econômicas, sobretudo daquelas empresas de comunicação digital (para alguns de natureza diretamente publicitária), a exemplo do WhatsApp, Facebook e Instagram, calcadas nos cliques, nos toques após toques, transformando a impaciência dos usuários em pagamento de bônus aos acionistas. As big techs, estruturadas para promover a "cultura da atenção desatenta", não aceitam arreglos, haja vista implementarem estratégias de domínio no plano concorrencial entre elas.

O problema é que tal ambiência de transações culturais está posta no mundo da escola. Independentemente de as salas de aula possuírem televisores, internet, computadores, algum projeto para uso do celular como apoio didático. Docentes e discentes transitam da parte interna para a externa das unidades educativas, movimento no qual toda sorte de mensagens e acionamentos de dispositivos ocorrem. A pergunta a ser feita não é se já existe uma cultura da mídia em circulação, com os seus evidentes nexos e retroalimentações junto ao público, mas qual a natureza dela, como tratá-la, desvendá-la, torná-la possível aliada nos processos educativos voltados ao esclarecimento e à desreificação. Prosseguindo em nossa linha argumentativa: posicionar a interface comunicativa-educativa enquanto assunto a ser trabalhado tendo em vista, por exemplo, as salas de aula, significa não apenas reconhecer os vetores culturais que transitam pelos aparatos sociotécnicos, mas fazê-lo 


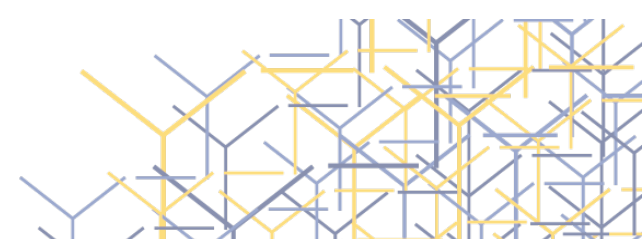

objetivando a estabelecer diálogos virtuosos com os discursos institucionais escolares.

\section{Amplitudes do aprender}

A questão concernente à interface da qual estamos tratando, carreia consigo, neste tópico, três termos pressupostos: saber/conhecer, informação (cuja qualidade, procedência, validade é assunto inescapável) e meios (basicamente os dispositivos). No primeiro caso, subsistem as perguntas clássicas: o que é o saber/conhecer? Ou ainda, saber/conhecer para quê e para quem? As mesmas perguntas, ou algo próximo delas, podem ser estendidas à informação e aos meios. Tais interrogantes tornam-se fulcrais quando trazemos os "ganchos de amarração" da interface para dentro das salas de aula.

E cabe relembrar que a comunicação, ao menos em seu plano mais geral e de dominância nos media, tende a operar a partir do eixo da informação, ou de um conhecimento demais diluído. Assim, o projeto confluente à educomunicação precisa promover exercícios sucessivos que montem e remontem a informação regulada no jornal, rádio, televisão, sites noticiosos, submetendo-a aos processos de desinterdição que a força educadora emancipatória pode ativar. Em uma palavra: falamos de perscrutar os variados planos dos sentidos e definir estratégias para apreendê-los, pensando-os enquanto fenômenos desenvolvidos a partir de certos lugares de produção social, ideológicos, e substanciados em estruturas discursivas. (MAINGUENEAU, 1998; CHARAUDEAU, 2006).

Tal ambiência que situa os processos formais de ensinoaprendizagem frente a uma nova realidade, passível de identificação nas "zonas de interface", convida a especializar o trabalhado levado a termo na sala de aula, considerando de modo analítico-crítico as referidas culturas midiáticas, seus dispositivos e linguagens. 
Aliás, a pandemia em presença vem forçando a se lançar mãos de recursos que antes pareciam pertencer, ao menos do ponto de vista institucional e em dimensão mais ampla, ao mundo fora dos muros escolares. O ensino remoto, por exemplo, mobiliza aparatos que eram utilizados pelos discentes e docentes, até há pouco, para finalidades pouco coincidentes com o cotidiano pedagógico formal. Sem querer adiantar o debate acerca da pós-pandemia e se haverá mudanças substanciais na forma-aula/presencial, o fato é que smartphones e computadores - para ficarmos em dois casos - ganharão maior abrangência no ensino formal.

Tudo isto nos leva ao ponto de mobilizar as concepções e as estratégias do aprender quando nos ocupamos em pensar os vínculos comunicação e educação, inclusive no referido empenho analítico-crítica para considerar o tema dos media na sala de aula. Nessa perspectiva, a educomunicação, em cujas bases conceituais está o ensino calcado nas trocas dialógicas e na construção participativa dos projetos pedagógicos, pode trazer significativo contributo no tratamento das sociotécnicas na escola. Aliás, a Base Nacional Comum Curricular (BNCC) já lança alguma luz sobre o problema ao lembrar que entre as competências e habilidades a serem desenvolvidas junto aos alunos e alunas estão as de apreender o papel da comunicação (lá traduzido sob o enunciado de cultura digital), e do pensamento crítico e cientifico. En passeant: não deixa de recender ironia um documento oficial do MEC desdizer as atuais políticas do governo federal ocupado em desqualificar os/as educadores/as e a pesquisa científica.

\section{Enfim}

Ao longo deste texto sumariamos algumas pistas que podem contribuir na discussão envolvendo a interface comunicativo-educativa. Estamos envolvidos por um momento histórico de alta complexidade - 
acentuada pela pandemia e, no caso brasileiro, por uma necropolítica de voltagem extremamente desagregadora - no interior da qual as sociotécnicas jogam papel relevante nas maneiras de os sujeitos serem e existirem. As tensões desta circunstância terminam, por diversas razões, nas salas de aula (ou fora delas, haja vista a repentina mudança de "modelo", tendo a escola que conviver, inesperadamente, com as diversas formas de ensino remoto), que passam a enfrentar o "instante de perigo" representado pela fricção entre as culturas analógicas e digitais. Esses deslizamentos costumam trazer consigo um debate fora do lugar envolvendo, de um lado, as armadilhas tecnocêntricas e, de outro, as evasões tecnofóbicas.

Daí a sugestão, motivada pela pesquisa que realizamos e citada em outros momentos deste artigo, em prover as escolas (ou outras instituições voltadas à educação informal ou não formal) de projetos educomunicativos orientados segundo lineamentos dialógicos e interacionais. Tal inflexão entende os media e suas tecnologias como dispositivos que precisam ser pensados e operados segundo orientação analítico-crítica. Em instante no qual as fake news ganham domínio, celeridade e profundidade; as máquinas de produzir ódio se afirmam como adversárias da tolerância e do esclarecimento; as redes e plataformas digitais agem enquanto força publicitária à captura de atenção - ou, se quisermos de monetização -; os dados se transformaram em novo poder colonizador (COULDRY; MEJIAS, 2019), ganha relevância o papel da educação como prática da autonomia e da liberdade (FREIRE, 2006). Afinal, além da possível regulamentação das ditas redes e plataformas (trabalho hercúleo e de duvidoso sucesso), da criação de limites para o modus operandi da indústria de dispositivos (algo incontornável à luz do presente estágio do capital), é a capacidade de discernir (afora medidas legais sempre cercadas de óbices e zonas cinzentas) que pode colaborar na criação de vacinas contra o vírus da notícia maliciosa, do engodo, da negação da ciência e da pesquisa. E, até 


\section{tríade}

segunda ordem, um dos lócus apropriados para ativar o discernimento, elaborar o conhecimento crítico, estimular a cidadania comunicativa (MATA, 2006), é a educação associada aos projetos socialmente emancipadores.

\section{Referências}

ANDRADE, Carlos Drummond. A rosa do povo. São Paulo: Companhia das Letras, 2012.

BENJAMIN, Walter. Teses sobre o conceito de história. Obras escolhidas v. 1. Magia e técnica, arte e política. Ensaios sobre literatura e história da cultura. São Paulo: Brasiliense, 1987.

BOURDIEU, Pierre. O poder simbólico. Rio de Janeiro: Bertrand Brasil, 2012.

CHARAUDEAU, Patrick. Discurso das mídias. São Paulo: Contexto, 2006.

CITELLI, Adilson (Org.). Comunicação e educação. Os desafios da aceleração social do tempo. São Paulo: Paulinas, 2017.

COULDRY, Nick; MEJIAS, Ulises A. How data is colonizing human life and appropriating it for capitalism. Redwood City: Stanford University Press, 2019.

FREIRE, Paulo. Pedagogia da autonomia. São Paulo: Paz e Terra, 2006.

FREIRE, Paulo. Pedagogia do oprimido. São Paulo: Paz e Terra, 2005.

HEIDEGGER, Martin. A questão da técnica. Ensaios e Conferências. Petrópolis: Vozes, 2002.

HUI, Yuk. Tecnodiversidade. São Paulo: Ubu, 2020.

MAINGUENEAU, Dominique. Analyser les textes de la communication. Paris: Dunod, 1998.

MATA, Maria Cristina. Comunicación y ciudadanía. Problemas teóricopolíticos de su articulación. Revista Fronteiras, São Leopoldo, v. VIII, n. 1, p. 5-15, jan./abr. 2006.

MBEMBE, Achille. Necropolítica. São Paulo: n-1 edições, 2018. 


\section{tríade}

PIKETTY, Thomas. Capital e ideologia. Rio de Janeiro: Intrínseca, 2020.

TEZZA, Cristovão. A tensão superficial do tempo. 1 ed. São Paulo:

Todavia, 2020. 